\title{
Uma Avaliação Crítica das Estimativas de Produto Potencial para o Brasil
}

\section{Potential Output Estimates for Brazil: a Critical Assessment}

\author{
Ricardo Summa*
}

\begin{abstract}
Resumo: Com a implantação do Sistema de Metas de Inflação (SMI) no Brasil, ganhou importância a necessidade de medir o hiato do produto, que segundo o modelo do Novo Consenso em política econômica, que serve de inspiração teórica para o SMI, é a principal causa da inflação no longo prazo. O presente artigo visa avaliar criticamente os artigos e estudos feitos pelas instituições oficiais brasileiras (como por exemplo BACEN e IPEA) e acadêmicos que estimam o produto potencial para o Brasil. Avaliaremos a razoabilidade dos resultados empíricos produzidos por essas estimações e a aderência à teoria do Novo Consenso, que é a base de sustentação do modelo do SMI. Conclui-se que (1) quanto mais exógeno e determinado por fatores de oferta (estoques de fatores, seu uso eficiente e em níveis que não aceleram a inflação) é o produto potencial estimado, menor é a aderência empírica, devido a presença de hiatos significativamente negativos e persistentes; e (2) a tentativa de remediar tal método utilizando filtros estatísticos acaba por tornar o produto potencial endógeno e dependente do andamento do produto e da demanda efetiva, o que vai de encontro a teoria do Novo Consenso que sustenta o modelo.
\end{abstract}

Palavras-chave: Produto potencial. Modelo do Novo Consenso. Histerese.

Abstract: Since the beginning of operation of the inflation targeting system (ITS) in Brazil, it's turning more important to estimate the output gap, that according to the model that sustain theoretically the ITS - The New Consensus model - is the main cause of the long run inflation. The present paper aims to evaluate critically the studies and working papers written by researchers of brazilian official institutions (like Brazilian Central Bank and IPEA) and Universities that estimate the potential output for the Brazilian economy. We will evaluate the reasonability of the empirical findings produced by these estimations and the compatibility with the New Consensus theory, which is the theoretical basis of the model that sustain

Professor adjunto do Instituto de Economia da Universidade Federal do Rio de Janeiro (UFRJ). E-mail: rifsumma@yahoo.com. O autor agradece os comentários e sugestões de dois pareceristas anônimos. 
the ITS. We conclude that (1) the more exogenous and supply driven (stock of production factors, productivity and NAIRU) is the estimated potential output, the weaker are the empirical outcomes, in consequence of significant and persistent negative output gaps; and (2) that the attempt to fix this method with the use of statistical filters turns the potential output endogenous and depending on the role of the current output and effective demand, a result that is incoherent with the New Consensus theory that sustain the model.

Keywords: Potential output. New Consensus Model. Hysteresis.

JEL Classification: O40; E60.

\section{1 lntrodução}

Com a implantação do Sistema de Metas de Inflação (SMI) em 1999 no Brasil, ganhou importância a realização e divulgação de estudos sobre o a capacidade de produção de uma economia sem gerar inflação, ou seja, o produto potencial. Isso porque o modelo teórico adotado como pano de fundo para garantir o cumprimento da meta inflacionária - o modelo do Novo Consenso - diz que, grosso modo, a inflação se acelera quando o produto está acima do potencial e se desacelera quando está abaixo do potencial.

Segundo esta visão, descobrir qual é o hiato do produto - a diferença entre o produto efetivo e o potencial - é de vital importância para a condução de política econômica. Dessa maneira, é comum ver tentativas de estimação do produto potencial e do hiato do produto nos boletins de conjuntura e notas técnicas do IPEA, bem como nos working papers e relatórios de inflação do Banco Central (BACEN), ou seja, nos documentos oficiais que dão suporte técnico e ajudam na sustentação do SMI ${ }^{1}$.

O presente artigo busca avaliar criticamente as diversas maneiras de estimação do produto potencial seguidas pelos pesquisadores desses institutos oficiais. Analisar-se-á, assim, os problemas empíricos das estimações do produto potencial e do hiato de produto, bem como as hipóteses teóricas que estão por trás destas estimações.

O trabalho que segue se articula da seguinte maneira: na seção 2, discutiremos os modelos de crescimento do produto potencial liderados pela oferta. $\mathrm{Na}$ seção 3, será feita uma avaliação crítica das estimações do produto potencial para o Brasil no período recente. Por fim, conclusões e considerações finais serão feitas na seção 4.

$1 \quad$ É importante notar que diversos Bancos Centrais de outros países e instituições de pesquisa adotam as mesmas técnicas para estimar o PIB potencial (PALUMBO, 2008). 


\section{Modelo do Novo Consenso e a Teoria de Crescimento do Produto Potencial de Longo Prazo Determinado pela Oferta}

Um dos fundamentos do modelo do Novo Consenso em política econômica (BLINDER, 1997; ROMER, 2000; TAYLOR, 1997)², de inspiração novo-Keynesiana, é a ideia de que o produto potencial é determinado pelos fatores de oferta, e, portanto, é independente da evolução da demanda agregada e do produto efetivo. Esta visão do produto potencial está assentada na teoria neoclássica do valor e da distribuição, segundo a qual é a demanda por fatores (capital e trabalho) que tende a se ajustar à oferta de fatores, exógena, por meio de um processo de substituição direta e indireta que faz com que a variação da oferta de um fator desencadeie um processo de mudança de preços relativos entre os fatores e assim altere a técnica de produção (relação entre capital e trabalho). Como consequência, há uma tendência ao pleno emprego dos fatores de produção (SERRANO, 2001).

A teoria neoclássica do valor e da produção é a base dos modelos de crescimento exógeno (do tipo Solow, por exemplo) e do crescimento endógeno (CESARATTO; SERRANO, 2002), que são utilizados como teoria do crescimento da capacidade produtiva dentro do arcabouço do modelo do Novo Consenso. ${ }^{3}$

Com o passar do tempo e com as evidências empíricas que os estoques de fatores não são plenamente utilizados, principalmente o fator trabalho, passou-se a utilizar a ideia de taxa natural de desemprego. Segundo esta ideia, o potencial da economia não é mais a plena utilização do estoque do fator trabalho, mas sim a utilização do trabalho em um nível que compatibilize a demanda e a oferta por trabalho e não gere pressões inflacionárias. Qualquer taxa de desemprego abaixo da natural desencadeia um processo de aumento de salários, levando a um aumento da inflação dos preços e derruba a demanda agregada, restabelecendo o desemprego em sua taxa natural.

No debate mais contemporâneo, na análise novo-keynesiana, o conceito de taxa natural de desemprego que equilibra oferta e demanda por trabalho dá lugar ao conceito de NAIRU, sendo este definido como a taxa de desemprego que não acelera a inflação. Nota-se, portanto, que é um conceito mais baseado na empiria, e a NAIRU pode diferir da taxa natural de desemprego se houver imperfeições do mercado de trabalho. O produto potencial, dessa maneira, não reflete mais o

2 É importante deixar claro que a versão do Novo Consenso aqui adotada é aquela mais aplicada para o uso de política econômica na prática do modelo novo-keynesiano, conhecido como o "modelo de três equações" (CARLIN; SOSKICE, 2010), e que começa a aparecer nos manuais de Economia de graduação (MANKIW, 2010). Não estamos aqui falando da versão mais microfundamentada e que incorpora elementos dos ciclos reais de negócios, a chamada "Nova Síntese Neoclássica".

3 Segundo Taylor, "[...] the long-run real GDP trend - or potential GDP - can be understood using the growth model that was first developed by Robert Solow and that has now been extended to make 'technology' explicitly endogenous (TAYLOR, 2000, p. 2)" 
estoque total dos fatores e sua eficiência, mas estes multiplicados pelas taxas de desemprego (e de utilização de capacidade) que não aceleram a inflação. O produto potencial passa a ser o nível de produto que não acelera a inflação.

No modelo do Novo Consenso em política econômica, quando o produto está acima (abaixo) do potencial, a inflação se acelera (ou desacelera), o Banco Central, por meio de uma função de reação, aumenta (diminui) a taxa real de juros e faz com que o produto efetivo e a demanda efetiva convirjam para o potencial.

Dessa maneira, a tendência do produto potencial depende do crescimento do estoque dos fatores de capital e trabalho e do crescimento da produtividade total desses fatores, sendo que os fatores são limitados por suas taxas não aceleradoras da inflação. A demanda agregada não exerce nenhuma influência sobre o produto potencial, apenas sobre o produto efetivo no sentido de compatibilizálo com o produto potencial. Dessa maneira, espera-se que a tendência de longo prazo do produto seja determinística, não afetada pelos choques de curto prazo $^{4,5,6}$.

Na seção seguinte, analisaremos as dificuldades empíricas e teóricas enfrentadas pelas estimações de produto potencial para o caso brasileiro, avaliando em que medida estes são estimados de acordo com a teoria de produto potencial utilizada pelo modelo do Novo Consenso, que diz que este deve ser determinado pelos fatores de oferta. Conclusões serão apresentadas na seção 4.

4 Ocorre que há uma forte evidência empírica de histerese forte no produto, ou seja, de que a tendência do produto é estocástica. O trabalho de Nelson e Plosser foi o primeiro a encontrar raiz unitária na série do produto para os EUA. Para uma análise mais recente sobre a existência de raiz unitária no produto dos EUA, ver Braga (2006). Para o Brasil, Serrano e Braga (2008) encontraram evidências de que a série de produto tem raiz unitária. Barbosa-Filho (2004) mostra que o modelo ARIMA (pressupõe existência de raiz unitária), é uma boa representação da série do PIB brasileiro. Libânio (2008) encontrou - após fazer um teste de raiz unitária em painel para diversos países da América Latina - a existência de raiz unitária no PIB desses países, no período 1970-2004. Como consequência, choques (de oferta ou de demanda) no produto efetivo tendem a afetar sua tendência. Assim, o produto potencial não é independente do produto corrente, ou em outras palavras, a natureza do ciclo econômico e da tendência é a mesma. Existem duas possíveis explicações para essa evidência empírica: os modelos do Ciclo Reais de Negócios e os modelos de Crescimento Liderados pela Demanda.

5 O modelo dos Ciclos Reais de Negócios desconsidera os efeitos da demanda agregada sobre o produto mesmo no curto prazo, e explica a oscilação do produto em torno da tendência como decorrente de mudanças pelo lado da oferta, como mudanças no ritmo do crescimento da mudança tecnológica. Dessa maneira, o produto potencial é afetado pelos choques de oferta de curto prazo, fazendo com que a tendência da série seja estocástica. Porém, tal teoria esbarra em diversas dificuldades empíricas quando confrontada com fatos estilizados. Primeiro, porque é irrealista achar que o ciclo de curto prazo é mais conduzido pela oferta do que pela demanda. Outro problema é que, se o ciclo for conduzido por fatores de oferta, os auges do ciclo, decorrentes de aumento de produtividade, deveriam gerar hiatos negativos e movimentos de diminuição de preço, e a inflação seria assim, anticíclica. (Ver SERRANO, 2007, p. 58)

6 Outra maneira de explicar a evidência empírica de tendência estocástica do produto vem da ideia das Teorias do Crescimento Liderado pela Demanda. Afinal, tanto choques de oferta quanto de demanda poderiam alterar a tendência do produto. Dessa maneira, o crescimento do produto potencial poderia ser liderado pela demanda efetiva e pelo investimento (ver SERRANO, 2007). 


\section{Estimações do Produto Potencial para o Brasil}

Nessa seção, serão expostos os métodos de estimação do produto potencial para o Brasil e avaliados em que medida estes seguem a proposição teórica do modelo do Novo Consenso de utilizar um produto potencial exógeno e quais os resultados empíricos gerados. ${ }^{7}$

\subsection{Produto potencial exógeno estimado pela Função de Produção}

A estimação do produto potencial pelo "método da função de produção" segue a teoria do produto potencial utilizada pelo modelo do Novo Consenso, ou seja, ela reflete a ideia de que o produto potencial é exógeno e não deve sofrer influências do andamento do produto corrente e da demanda agregada.

Por esse método, é estimada uma série temporal do produto potencial que deve levar em conta o estoque dos fatores de produção, seu uso eficiente (produtividade total dos fatores) e a utilização desses fatores em um nível que não acelera a inflação.

Com a série estimada do produto potencial, é possível avaliar se o hiato do produto - a diferença entre o produto efetivo e o potencial - é positivo ou negativo, o que pelo arcabouço do modelo do Novo Consenso é um importante indicador da existência de pressões inflacionárias e de monitoramento por parte da Autoridade Monetária (AM) para os propósitos de política econômica.

\subsubsection{O método de estimação}

A estimação do produto potencial exógeno por meio de uma função de produção consiste em estimar o produto potencial por meio de variáveis que encontram respaldo na teoria neoclássica de crescimento econômico ${ }^{8}$. Esse método consiste em estimar o produto potencial por meio de uma função de produção que leve em conta o estoque potencial dos fatores de produção, a produtividade total destes fatores e seus níveis de utilização que não geram pressões na taxa de inflação ${ }^{9}$. É importante notar que esse produto potencial neoclássico representado por uma função de produção é baseado na teoria do equilíbrio geral e seus mecanismos de substituição, no produto marginal decrescente dos fatores e os retor-

7 Esses estudos sobre o produto potencial brasileiro são divulgados por órgãos oficiais, por exemplo, pelo BACEN e IPEA. No BACEN, é possível encontrar estimativas do produto potencial em seus relatórios trimestrais de inflação (BACEN, 1999, 2000b, 2003, 2004, 2005) e em seus working papers. Esses métodos que serão expostos também são divulgados por diversas instituições internacionais, como a OCDE, BCE, FMI e outros (ver Billmeier (2004) para um exemplo de estudo do FMI e como estes são parecidos com aqueles realizados no Brasil).

8 Para uma resenha mais detalhada sobre o método econômico de estimar o produto potencial brasileiro, incluindo os modelos de crescimento endógeno, ver Lucas (2008).

9 Do ponto de vista teórico, tanto a NAIRU quanto a NAICU devem ser extraídas da estimativa da curva de Phillips. 
nos constantes de escala de todos os métodos de produção, pressupondo assim o pleno emprego dos fatores decorrentes da operação dos mecanismos de mercado (Ver SERRANO, 2001; CESARATTO; SERRANO, 2002). Tal método em geral supõe uma função de produção do tipo Cobb-Douglas ${ }^{10}$ para o produto potencial:

$$
Y_{t}^{*}=A_{t}\left(K_{t} N A I C U_{t}\right)^{\alpha}\left(L_{t}\left(1-N A I R U_{t}\right)\right)^{1-\alpha}
$$

$\mathrm{Na}$ equação acima, $Y_{t}^{*}$ é o nível do produto potencial; $K_{t}$ é o estoque de capital e NAICU é o nível de utilização da capacidade que não acelera a inflação; $L_{t}$ é o estoque do fator trabalho e NAIRU é a taxa de desemprego que não acelera a inflação; $A_{t}$ é a produtividade total dos fatores; e por fim $\alpha$ é a contribuição do fator capital para o produto (o que torna $(1-\alpha)$ a contribuição do fator trabalho para o produto).

Para calcular empiricamente o produto potencial por esse método, é necessário saber o tamanho dos estoques de capital e de trabalho na economia; a produtividade total dos fatores (PTF); a NAIRU e a NAICU; e o parâmetro $\alpha$.

O método usualmente utilizado na literatura brasileira para a estimação de cada uma dessas variáveis depende das seguintes etapas:

(a) O estoque de capital é construído pelo método do inventário perpétuo, que consiste basicamente em estimar um estoque de capital em um ponto bem longe do tempo, e acrescentar a cada período o fluxo de investimento e descontar a depreciação ${ }^{11}$.

(b) Com relação ao estoque de trabalho, o método utilizado é obter a série da população economicamente ativa (PEA) e corrigir pela taxa de participação (relação entre PEA/PIA) para levar em conta o efeito desalento ${ }^{12}$.

(c) O parâmetro $\alpha$, que mede a contribuição do capital para o produto, é obtido pelos dados da contabilidade nacional. A contribuição do capital ao produto é suposta como sendo igual à proporção da remuneração do capital sobre a renda nacional. Isso quer dizer que está sendo feita duas fortes imposição teórica, (1) que é a existência de uma infinidade de maneiras de produzir o produto de forma eficiente combinando capital e trabalho com retornos constantes de escala; e (2) que a elasticidade de substituição é unitária, o que implica que as participações do capital e trabalho na renda têm que ser iguais à contribuição destes fatores para o produto.

(d) A PTF é obtida via resíduo entre a série de produto efetivo e as séries da contribuição dos fatores ao produto, conforme método descrito a seguir:

\footnotetext{
10 O uso da função de produção Cobb-Douglas traz consigo a imposição teórica de elasticidade unitária de substituição entre os fatores, que faz com que os fatores sejam substituídos em iguais proporções às variações em seus preços.

11 Como nos mostra Barroso (2007), o pior problema a ser enfrentado por esse método é escolher a taxa de depreciação adequada, pois divergências desta acabam tendo efeito permanente e divergente sobre o nível de produto potencial.

12 O efeito de saída de trabalhadores do mercado de trabalho quando passam um bom tempo desempregados.
} 
O produto efetivo pode ser descrito pela equação abaixo:

$$
Y_{t}=A_{t}\left(K_{t} c_{t}\right)^{\alpha}\left(L_{t}\left(1-u_{t}\right)\right)^{1-\alpha}
$$

O produto, $Y_{t}$, será definido pelos estoques dos fatores capital e trabalho multiplicados por sua utilização efetiva (com $c_{t}$ o nível de utilização da capacidade instalada e $u_{t}$ a taxa de desemprego) mais a produtividade total dos fatores. Assim, com as séries estimadas dos estoques de capital e trabalho, os dados da contabilidade nacional para $\alpha$, em conjunto com as séries de produto efetivo, taxa de desemprego ${ }^{13}$ e NUCI da indústria, calcula-se a PTF segundo a equação abaixo:

$$
\ln A_{t}=\ln Y_{t}-\operatorname{aln}\left(K_{t} c_{t}\right)-(1-\alpha) \ln \left(L_{t}\left(1-u_{t}\right)\right.
$$

A série da PTF obtida por este método em geral é bem irregular, cíclica, e é procedimento comum a suavização desta série pela aplicação de um filtro estatístico para encontrar uma tendência da produtividade.

Cabe, aqui, tecer algumas considerações ao método de obtenção da série de PTF. Primeiramente, de um ponto de vista mais geral, tal série, como é calculada como resíduo do PIB efetivo, acaba sendo pró-cíclica e altamente correlacionada com o produto efetivo (mesmo corrigindo o estoque de capital e trabalho pelas taxas de emprego e NUCI, que dependem da demanda e são pró-cíclicas), como demonstram Barbosa-Filho (2004) e Palumbo (2008). Isso está ligado ao fato de para estimar a PTF entre a relação do produto efetivo e uma média ponderada entre os fatores de produção é necessário supor que o método de produção efetivamente utilizado apresenta retornos constantes de escala. Assim, as relações técnicas capital-produto e trabalho-produto são supostas fixas, e o que varia ao longo do ciclo é a utilização desses fatores. Porém, a hipótese de que a produtividade do trabalho é fixa ao longo do ciclo é altamente implausível, havendo fortes evidências de que a produtividade do trabalho é pró-cíclica. Dessa maneira, esse fato acaba aparecendo nas estimativas da PTF, na forma de irregularidade e pró-ciclicalidade.

A série de PTF calculada por esse método para o caso brasileiro, na grande maioria dos trabalhos, exibe uma tendência negativa na década de 80 até início dos 90 na economia brasileira. Seria um fato bastante difícil entender um regresso técnico durante quase uma década, pois a própria ideia de progresso técnico requer que ele seja tendencialmente positivo. Porém, vimos que na verdade por esse método a PTF capta o caráter pró-cíclico da produtividade do trabalho. Uma vez que o crescimento da demanda agregada e do produto efetivo diminuiu de patamar no período em questão, a explicação do "regresso técnico" pelo lado da

13 A taxa de emprego é calculada pela relação (1 - taxa de desemprego), e a taxa de desemprego em geral é obtida pelas pesquisas do IBGE. 
demanda - diminuição da produtividade do trabalho na fase baixa do ciclo - parece uma hipótese muito mais plausível ${ }^{14}$.

Voltando aos passos necessários para calcular o produto potencial conforme a equação (1), uma vez calculados os estoques de capital e trabalho, a PTF e o parâmetro $\alpha$, resta estimar a Taxa de Desemprego que não Acelera a Inflação (NAIRU) e o Nível de Utilização da Capacidade que não Acelera a Inflação (NAICU).

e) Para ser condizente com a teoria do produto potencial exógeno, é de se esperar que os níveis de utilização dos fatores de produção que não aceleram a inflação reflitam características estruturais, institucionais do mercado de trabalho, de capital e de produto, e portanto, como fatores do lado da oferta devem ser estáveis. Assim, esse método exógeno consiste em tentar estimar parâmetros de equações do tipo curva de Phillips para obter os valores fixos da NAIRU e NAICU.

Esse procedimento de apresentar a NAIRU e NAICU como constante ao longo do tempo é proposto por Silva Filho (2001), Jayme Júnior e Souza Júnior (2004) e Barroso (2007). Porém, ao invés de estimar uma curva de Phillips e calcular a NAIRU e NAICU por meio dos parâmetros obtidos, eles simplesmente estabelecem arbitrariamente um valor médio e fixo da taxa de desemprego efetiva para definir a NAIRU e um valor limite razoável de utilização da capacidade que não acelera a inflação, a NAICU.

A NAIRU e a NAICU estabelecida por esses autores gira em torno de $5 \%$ e 85\%, respectivamente. É importante notar que esses dados não têm a principio nenhuma relação com a inflação, nem com a aceleração da inflação, pois não são derivados de estimativas dos parâmetros de uma curva de Phillips aceleracionista.

Com a obtenção de todas as informações acima listadas, é possível calcular a série de produto potencial pelo método exógeno, embasado na teoria neoclássica do valor e da distribuição e que é utilizado pelo modelo do Novo Consenso discutido na seção 2 .

\subsubsection{Avaliação dos resultados}

Os resultados da estimação do produto potencial e do hiato de produto por esse método nos três trabalhos citados diferem um pouco entre si, e se referem a períodos amostrais diferentes.

14 Ainda que o método utilizado gere resultados endógenos e dependentes do andamento do produto efetivo para a PTF, e a queda desta reflita a queda da taxa de crescimento da demanda agregada e do produto efetivo, Silva Filho (2001) parece ignorar o corolário do método empregado ao citar elementos não incorporados ao modelo, como a instabilidade macroeconômica, a instabilidade político-institucional, um sistema judiciário pouco eficiente, protecionismo comercial, corrupção e diminuição dos investimentos em infraestrutura como causadores da queda da produtividade total dos fatores. 
Silva Filho (2001) encontra um hiato bem assimétrico para baixo durante todo o período estimado (1980-2000), sendo positivo apenas no ano de 1980 e levemente positivo no biênio 1986-1987, conforme pode ser visto no Gráfico 1.

Gráfico 1 - Hiato de produto

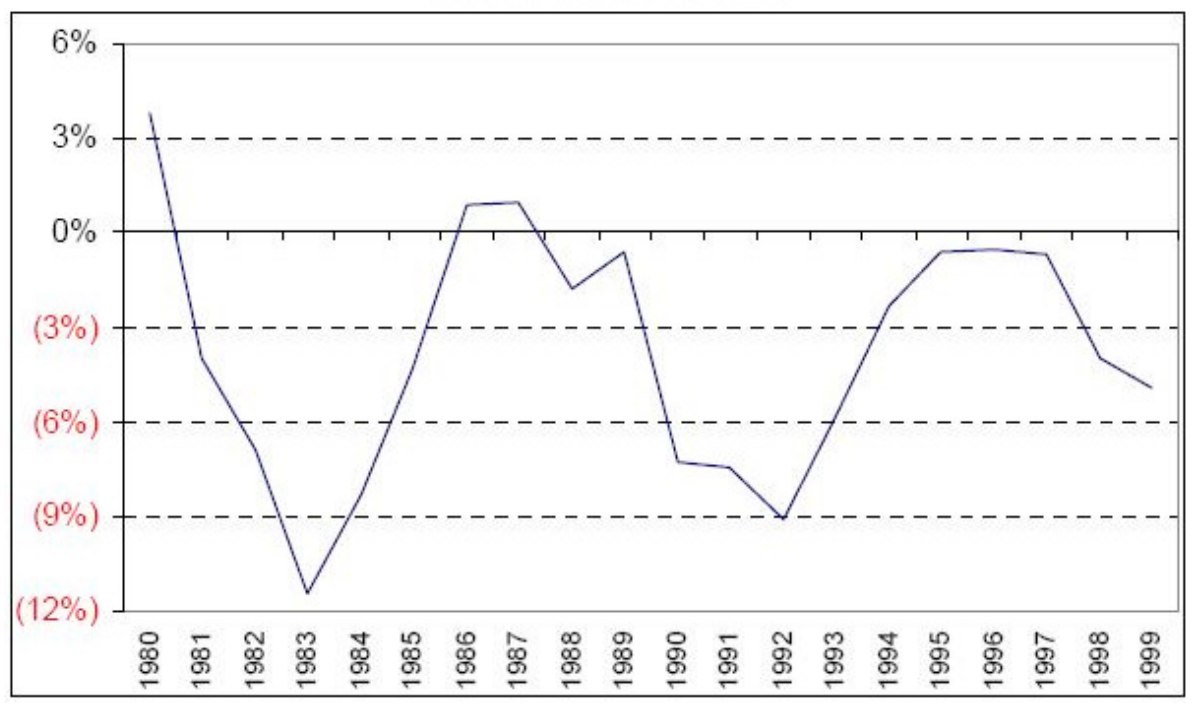

Fonte: Silva Filho (2001).

Souza Junior e Jayme Junior (2004) também encontram resultados assimétricos para o hiato do produto, refletindo o fato que o PIB efetivo se situa na maior parte da amostra abaixo do produto potencial, com os hiatos de poupança $\mathrm{a}^{15} \mathrm{calcu}$ lados também assimétricos para baixo.

Barroso (2007) encontra resultados ainda mais assimétricos do hiato do produto. Durante toda a amostra do PIB potencial estimado (1980-2005) o PIB efetivo se situa sempre bem abaixo do potencial, conforme se observa pelo Gráfico 2.

15 No modelo proposto por Souza Junior e Jayme Junior (2004), os autores estão mais preocupados em estimar os três hiatos (de poupança, fiscal e externo), que limitariam o investimento da economia, portanto ele apresenta seus resultados não em termos de hiato do produto, mas sim o hiato de hiato da poupança (diferença entre poupança potencial e investimento). 
Gráfico 2 - Relação entre produto efetivo e produto potencial

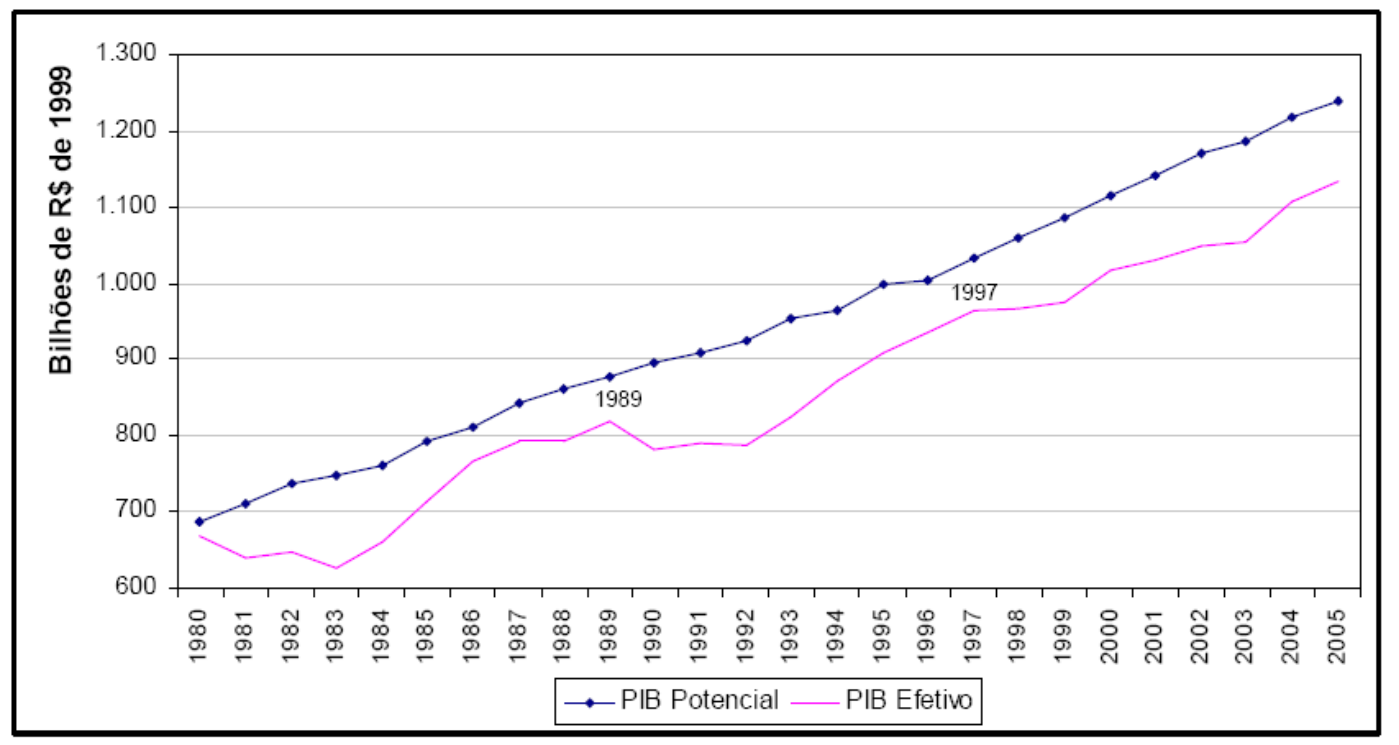

Fonte: Barroso (2007).

Os resultados em termos de hiato de produto produzidos pelo método de estimação que considera o produto potencial exógeno, e, portanto, que é condizente com a visão de produto potencial utilizada pelo modelo do Novo Consenso, acabariam gerando resultados empíricos contraditórios se combinados com a curva de Phillips aceleracionista, que também é um dos pilares teóricos do Novo Consenso.

Afinal, da maneira como é vista a determinação da taxa de inflação nesse modelo, um hiato negativo de produto tenderia a gerar uma desaceleração da inflação, que cairia e se manteria em patamar inferior. Como a série gerada de hiatos de produto é na maioria da amostra (SILVA FILHO, 2001; SOUZA JUNIOR; JAYME JUNIOR, 2004) ou em toda a amostra (BARROSO, 2007) negativa, tais hiatos estimados deveriam levar a conclusão que a inflação de longo prazo observada deveria apresentar uma tendência continua de desaceleração. Considerando o período longo em questão e o tamanho dos hiatos estimados, tal método poderia ocasionar em uma deflação de longo prazo, tendo em vista a ocorrência de tantos choques de demanda negativos.

Cabe ainda uma última observação sobre o método em questão. Tal método não pode ser considerado totalmente exógeno pois a série da PTF utilizada para construir o produto potencial é obtida via resíduo do produto efetivo e acaba se comportando de maneira pró-cíclica. Entretanto, esse método, comparado com os que veremos pela frente, é o que incorpora mais elementos exógenos e o que seria mais fiel ao conceito de produto potencial teórico utilizado no modelo do Novo Consenso. 


\subsection{O Produto Potencial Medido pelos Filtros Estatísticos}

Uma segunda maneira de estimar o produto potencial consiste em: 1. Considerar que este pode ser medido pela tendência de longo prazo do produto efetivo; e 2. Aplicar um filtro estatístico sobre a série do produto efetivo para calcular a tendência de longo prazo e chamar esta tendência calculada de produto potencial.

É importante fazer aqui duas observações que serão mais bem detalhadas nas próximas subseções. Primeiro, que tal tendência calculada, na verdade, nada mais é do que uma média móvel da própria série observada. E que existem outros métodos denominados filtros multivariados que incorporam na variação da tendência (calculada como média móvel da série observada) informações referentes a outras séries. Por exemplo, o cálculo do produto potencial por um filtro multivariado será uma média móvel da série do produto corrente, porém outras informações como a inflação são utilizadas para adicionar variações nessa tendência de longo prazo.

Dessa maneira, o produto potencial obtido por esses filtros é incompatível com o produto potencial teórico do modelo do Novo Consenso, que deve ser determinado apenas pela evolução dos estoques dos fatores e de seu uso eficiente, levando em conta as taxas de utilização não aceleracionistas (NAIRU e NAICU), e, portanto, insensivel a variações do produto efetivo.

\subsubsection{Os filtros univariados}

Um filtro estatístico consiste, grosso modo, em extrair da série efetiva do produto uma tendência. O produto potencial estimado por esse método será a tendência de longo prazo do produto efetivo.

O filtro estatístico mais tradicional é o filtro Hodrick-Prescott (filtro HP) univariado, que consiste em suavizar uma série histórica efetivamente observada ${ }^{16,17}$. A série não observada é gerada ao minimizar o quadrado da diferença entre a série efetiva e a tendência, bem como o quadrado da diferença entre a variação da tendência em $\mathrm{t}+1$ e $\mathrm{t}$ :

16 É importante notar que os trabalhos que têm como foco principal a estimação do produto potencial, em geral não se contentam com a simples aplicação do filtro HP univariado na série do produto efetivo. Porém, a grande maioria de trabalhos que tem como foco principal estimar uma curva de Phillips e utilizar o hiato do produto como medida de pressões de demanda, em geral aplicam um filtro HP para calcular o hiato, como é o caso no Brasil dos artigos de Portugal (2005), Moreira et al. (2007), Bevilaqua, Mesquita e Minella (2007), entre outros. Também é muito utilizado para efeito de comparação com outros métodos de estimação, tal como em Araújo et al. (2004), Lima e Britto (2008), Araujo e Guillén (2008).

17 Por exemplo, o próprio trabalho que justifica a implementação do sistema de metas de inflação no Brasil propõe que uma das melhores maneiras de estimar o produto potencial é pela aplicação do filtro HP (BOGDANSKI et al., 2000). Nos trabalhos de organismos internacionais como o FMI, $\mathrm{OCDE}, \mathrm{BCE}$, entre outros, a prática de uso de filtros estatísticos é bastante disseminada para a estimação do produto potencial (PALUMBO, 2008). 


$$
\left\{Y_{t}^{*}\right\}_{t=1}^{\mathrm{T}}=\operatorname{argmin}\left\{\Sigma_{t=1}^{\mathrm{T}}\left(\ln Y_{t}-\ln Y_{t}^{*}\right)^{2}+\lambda\left[\left(\ln Y_{t+1}^{*}-\ln Y_{t}^{*}\right)-\left(\ln Y_{t}^{*}-\ln Y_{t-1}^{*}\right)\right]^{2}\right\}
$$

Com $Y_{t}$ o produto efetivo; $Y_{t}^{*}$ o produto potencial; e o parâmetro $\lambda$ é uma medida de suavização, ou seja, ele regula a variabilidade da tendência ${ }^{18}$. O produto potencial calculado pelo filtro HP gera uma série de hiatos simétricos, conforme pode ser observado pelo Gráfico 3.

Gráfico 3 - Hiato do produto calculado pelo filtro HP

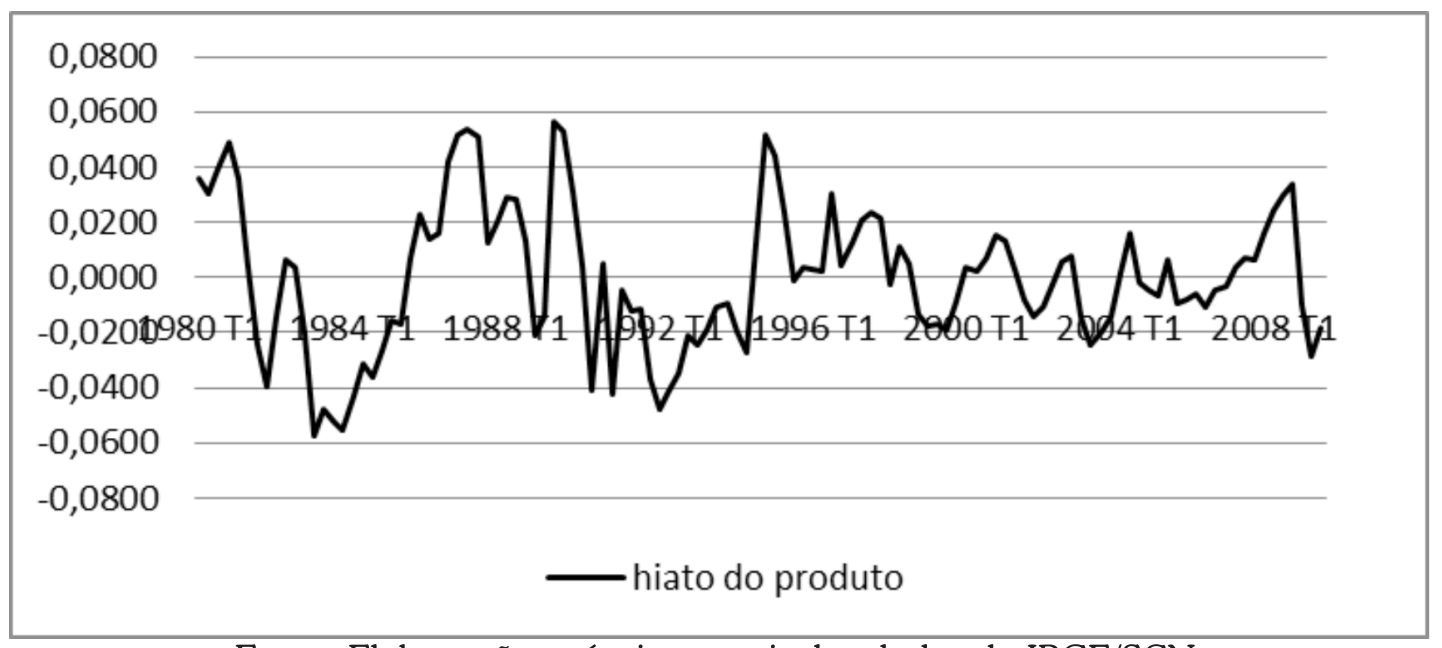

Fonte: Elaboração própria a partir dos dados do IBGE/SCN.

É importante notar que os hiatos de produto gerados pelo filtro HP são simétricos por construção, pois como este é calculado por uma espécie de média móvel do produto corrente, às vezes o produto potencial estará acima do efetivo e às vezes abaixo.

Outros filtros univariados também são aplicados em trabalhos empíricos de estimação do produto potencial (ARAÚJO et al., 2004; BACEN, 2007; ARAUJO; GUILLÉN, 2008), tal como o Filtro Band Pass ${ }^{19}$, e os modelos de componentes não

18 Cabe notar que o parâmetro de suavização da tendência tem um valor imposto de maneira arbitrária e sem nenhum fundamento teórico. Outro problema com o filtro HP é que ele apresenta instabilidade de estimação no fim da amostra, pois os últimos dados calculados pelo filtro HP são influenciados pelos novos dados que serão incorporados na amostra. Este fato compromete a previsão a curto e médio prazo do produto potencial (para o caso brasileiro, ver Barbosa-Filho (2009)). Além disto, o Filtro HP não revela mudanças estruturais e pode produzir ciclos espúrios na série do produto potencial.

19 Esse filtro surgiu para corrigir um problema do Filtro HP, que não distingue entre fatores sazonais e estruturais. Tal técnica de extração de tendência consiste em aplicar filtro de alta e baixa frequência à amostra, de maneira que no primeiro sobrem apenas os componentes de flutuação de curto prazo e no segundo apenas os componentes de flutuação de longo prazo. Para uma análise mais detalhada, ver Barbosa-Filho (2004). 
observados $^{20}$ univariado (entre os quais decomposição de Beveridge-Nelson ${ }^{21}$ ). É importante notar que todos esses métodos estatísticos, a despeito da diferença de grau de sofisticação matemática, consistem em extrair tendência da série do produto efetivo. Isso quer dizer que, por construção, o produto potencial será afetado pelo produto efetivo.

\subsubsection{Filtros Multivariados}

Os filtros multivariados são aqueles que levam em conta mais do que uma série observada para calcular a tendência. O produto potencial calculado por esse método será em parte determinado pela média móvel do produto corrente, porém outras informações são incorporadas para tal estimação, como, por exemplo, a inflação.

O principal método de filtros multivariados utilizado para calcular o produto potencial é o método dos componentes não observados multivariado, que consiste em dividir a série do PIB em um componente de tendência e outro cíclico e, além disso, adicionar equações estruturais como uma curva de Phillips e/ou uma equação de Okun. Em BACEN (2007) e Araújo e Guillén (2008), um modelo desse tipo é estimado, tal que:

$$
\begin{gathered}
\Delta Y_{t}=\Delta Y_{t}^{*}+\left(Y_{t}^{c}-Y_{t-1}^{c}\right)+\Delta s_{t} \\
\pi_{t}=a \pi_{t-1}+b \pi_{t-2}+c Y_{t-1}^{c}+\varepsilon_{1, t} \\
u_{t}-\text { nairu }_{t}=d\left(u_{t-1}-\text { nairu }_{t-1}\right)+f Y_{t-1}^{c}+\varepsilon_{2, t}
\end{gathered}
$$

A equação (5) demonstra que a série de crescimento do produto efetivo, $\Delta Y_{t}$, é decomposta entre os componentes de tendência $\left(\Delta Y_{t}^{*}\right.$, taxa de crescimento do produto potencial), ciclo $\left(\left(Y_{t}^{c}-Y_{t-1}^{c}\right)\right.$, variação do hiato do produto) e variação da sazonalidade, $\Delta s_{t}$. A equação (6) estabelece uma curva de Phillips que relaciona

20 Nesse processo de decomposição mais geral, a série do produto pode ser decomposto em tendência estocástica (o produto potencial) mais um ciclo estacionário (o hiato). Araújo et al. (2004) citam dois exemplos de método de componentes não observados, entre eles o método local em que o produto é modelado por um passeio aleatório (tendência) e um ruído branco (hiato); e o método de Watson, em que a tendência estocástica é definida por um passeio aleatório com deslocamento e o ciclo é definido por um AR(2). Ver Araújo et al. (2004, p. 7). A vantagem desses métodos é que não gera um viés tão forte no fim da amostra (SOUZA JUNIOR, 2005).

21 Essa técnica de decomposição assume que a série pode ser dividida em um componente permanente (modelado por um passeio aleatório com deslocamento) e um componente transitório (um autorregressivo estacionário). O produto seria então definido por um ARIMA (p, 1, q). Ver Araújo et al. (2004) para mais detalhes. 
inflação, $\pi_{t}$, com hiato do produto ${ }^{22}$. A equação de Okun (7) relaciona a diferença entre a taxa de desemprego, $u_{t}$, e a NAIRU com o hiato do produto.

Em seguida, são atribuídas propriedades estatísticas às séries dos componentes não observados (produto potencial, hiato e NAIRU) ${ }^{23}$. O passo seguinte é transformar o conjunto de equações em matrizes e aplicar um filtro de Kalman. Esse tipo de filtro calcula as séries não observadas de ciclo e tendência estimando os parâmetros das equações de variáveis observadas e não observadas em conjunto. No modelo em questão, estimou-se uma tendência a partir do produto efetivo corrigida pela variação da inflação e do desemprego. Isso significa que, se em um período a inflação foi mais alta, a tendência é corrigida para que o hiato seja maior que aquele que levasse em conta apenas a série do PIB efetivo.

A despeito da maior complexidade matemática e computacional que requer esse método ${ }^{24}$, tal procedimento continua sendo o de estimar o PIB potencial extraindo uma tendência da série do PIB efetivo, ainda que esta seja corrigida por outras informações. Mas como é demonstrado em BACEN (2007), tal procedimento gera uma série de hiato extremamente parecida com o hiato gerado pelo filtro HP univariado.

Lima e Brito (2008) ${ }^{25}$, estimam um modelo de componentes não observados multivariado ainda mais complexo matematicamente que o estimado pelo BACEN (2007). Eles chamam a série resultante extraída por esse método de "nível do produto que não acelera a inflação" (NAILO, em inglês) ao invés de chamar de produto potencial. Os autores constroem a NAILO que varia no tempo, para o período 1980- 2007. O método consiste em partir de uma curva de Phillips aceleracionista que relaciona variação da inflação com a diferença entre nível de produto efetivo

22 É importante notar que os autores não fazem nenhuma imposição para a curva de Phillips ser aceleracionista (ou seja, $a+b$ não é necessariamente igual à unidade). Dessa maneira, a taxa de desemprego que não acelera a inflação (NAIRU da equação 6) não deveria ser chamada de NAIRU, mas sim taxa de desemprego que não gera pressões inflacionárias, tal como concebeu Okun (1962) em seu trabalho original.

23 A taxa de crescimento do produto potencial é determinado por um processo autorregressivo com deslocamento estocástico; o hiato do produto é um processo autorregressivo estacionário; e a NAIRU é um passeio aleatório com deslocamento estocástico. Todos os erros são supostos normalmente distribuídos e com média zero, e o valor de suas variâncias é fixado arbitrariamente. Essa hipótese é arbitrária pois ao dizer que os erros têm média zero, está sendo excluída a possibilidade de que os "choques de oferta" tenham efeitos permanentes sobre a inflação.

24 Cabe aqui notar que o trabalho proposto por Guillén e Araujo (2008), os autores avaliam o desempenho dos hiatos medidos segundo uma série de métodos estatísticos (Filtro HP, Filtro HP com FP, Filtro Band Pass, Tendência linear, componentes não observados univariados e multivariados) e encontram que o que oferece melhor previsão dentro da amostra é o estimado por métodos de componentes não observados multivariados. Tal resultado parece à primeira vista confirmar que o método ao incorporar informações econômicas é superior aos métodos estatísticos univariados, porém como a tendência é construída para o hiato variar com a inflação, resulta da própria construção do método o resultado de melhor adequação à uma curva de Phillips em uma regressão.

25 Um modelo preliminar do mesmo autor com método semelhante pode ser encontrado em Lima (2001). 
e nível de produto que não acelera a inflação. Em seguida, define-se as variáveis não observadas e também a variância que segue um processo de mudança de Markov $^{26}$.

A partir daí, aplica-se um filtro ${ }^{27}$ para estimar os parâmetros e calcular a dinâmica da NAILO (variáveis não observadas). Mas tal método também consiste em extrair tendência da NAILO pelo produto corrente corrigida pela variação da inflação.

Podemos apontar um aspecto que decorre da adoção deste método: como a tendência é calculada pela série do produto efetivo corrigida pela variação da inflação, em períodos de inflação mais alta a tendência será "empurrada para baixo" para que esteja associada a um hiato maior. Dessa maneira, observa-se que o hiato é positivo e em níveis extremamente altos durante o período 1984-1991; em seguida é negativo e em um nível também alto até 1994. Após 1994, quando ocorre a estabilização da inflação, ele passa a oscilar de maneira mais parecida com o produto efetivo. Cabe notar que está implícito nessa formulação que toda variação da inflação é causada por pressões de demanda. No período 1984-1994, entretanto, a inflação foi claramente causada por crise de balanço de pagamento, desvalorização do câmbio e inércia, tal como demonstra Bastos (2001). Assim, parece que a utilização de filtros multivariados pode gerar ciclos espúrios, principalmente se o hiato é corrigido pela variação da inflação e esta muda drasticamente de caráter durante a amostra.

Enfim, a aplicação de filtros estatísticos nas séries observadas, sejam eles univariados ou multivariados, no fim das contas nada mais é do que a media móvel $\mathrm{da}(\mathrm{s})$ série(s) corrente(s). Portanto, o produto potencial calculado dessa maneira passa a ser endógeno e dependente do andamento do produto efetivo, e, portanto, contrário ao conceito de produto potencial teórico exógeno utilizado pelo modelo do Novo Consenso.

\subsection{O Produto Potencial Endógeno Calculado pela Função de Produção}

Vimos até aqui que o produto potencial calculado de maneira exógena por uma função de produção é o mais condizente com a teoria de produto potencial que embasa o modelo do Novo Consenso, pois em parte é endógeno devido ao cálculo da PTF por resíduo do produto corrente. Porém apresenta resultados empíricos insatisfatórios para explicar a inflação brasileira uma vez que este é con-

26 Nota-se que esse método também requer a imposição de um valor para a variância de maneira arbitrária.

27 Filtro de Kim, que é um filtro com matemática mais sofisticada que o filtro de Kalman, mas não deixa de ser também uma espécie de média móvel das variáveis observadas. Esse filtro estima os parâmetros das variáveis observáveis e não observáveis, concentrando a verossimilhança e estimando tais parâmetros por rotina numérica de otimização. A NAILO, que será a tendência extraída por esse filtro multivariado, é obtida suavizando o resultado das estimativas recursivas. 
cebido como o nível de produto que não acelera a inflação (e portanto, os hiatos negativos persistentes encontrados por esse método de estimação desacelerariam a inflação enquanto durassem).

Por outro lado, é prática comum estimar o produto potencial aplicando um filtro estatístico que calcula o produto potencial como uma espécie de média móvel do próprio produto corrente (alterando ou não a variabilidade dessa tendência com o uso de outras séries). Esse processo acaba por gerar um produto potencial endógeno e, portanto, dependente do andamento do produto corrente, abandonando a teoria de produto potencial exógeno utilizada pelo Novo Consenso.

Existe outra maneira de estimar o produto potencial, que, na verdade, é uma combinação entre os dois métodos discutidos acima. Trata-se de estimar o produto potencial pela Função de Produção, porém aplicar filtros estatísticos em algumas variáveis como a taxa de desemprego e utilização da capacidade para o cálculo da NAIRU e NAICU. Esse método produzirá também estimações endógenas do produto potencial, uma vez que este dependerá do andamento corrente da taxa de desemprego e do nível de utilização da capacidade observados na economia.

\subsubsection{Aplicação de filtros no método da Função de produção}

Souza Junior $(2005,2006,2007)$ segue os mesmos passos a) a d) do método do produto potencial exógeno estimado pela função de produção discutidos na seção 3.1. A diferença proposta por Souza Jr é que, ao invés de supor valores constantes para a NAIRU e a NAICU, a estimação da NAIRU e NAICU é feita pela aplicação de filtros estatísticos nas próprias séries efetivas de desemprego e $\mathrm{NUCI}^{28}$. Assim, utiliza a média móvel dessas séries observadas como sendo a taxa de desemprego e utilização de capacidade que não aceleram a inflação. No Gráfico 4, mostramos a extração da tendência de uma série de taxa de desemprego (SEADE/DIEESE).

28 Em geral, utiliza-se séries de utilização da capacidade da indústria calculadas pela FGV ou CNI como proxy para a economia como um todo. Souza Junior (2005) calcula a série de utilização da capacidade para diversos setores da economia brasileira e calcula uma série da utilização total ao ponderar esses níveis de utilização setorial por seus pesos no produto. Para a taxa de desemprego, utiliza uma mescla entre a pesquisa anual da PNAD e a série da taxa de desemprego da PME do IBGE. 
Gráfico 4 - NAIRU calculada por filtro HP

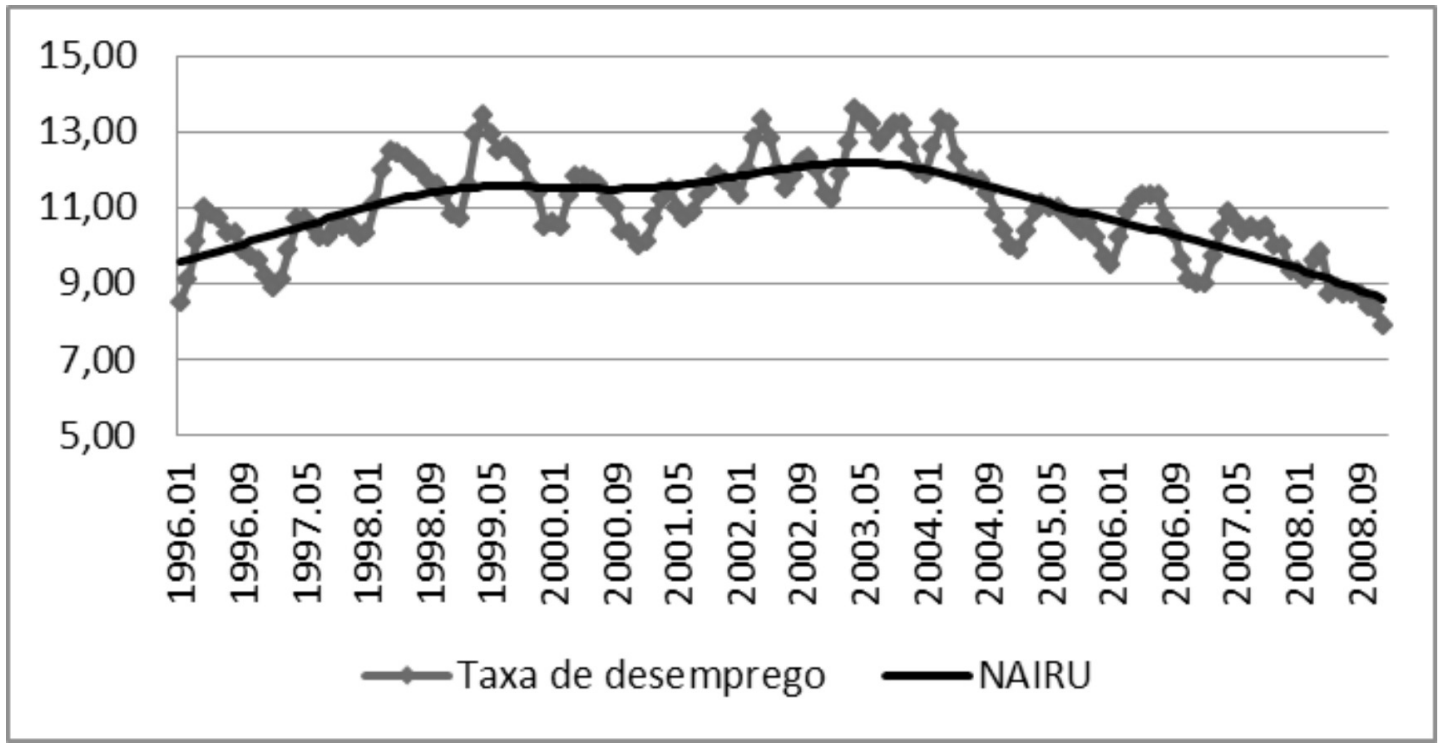

Fonte: Elaboração própria a partir de dados de SEADE/DIEESE.

O resultado, como pode ser visto, é que a extração da tendência da série faz com que a NAIRU seja uma espécie de média móvel da taxa histórica de desemprego. Em períodos em que a taxa de desemprego é alta, a NAIRU aumenta e em períodos em que a taxa de desemprego é mais baixa, a NAIRU diminui. Além disso, NAIRU, que por definição é a taxa de desemprego que não acelera a inflação, nesse caso é obtida sem nenhuma relação com inflação. Exercício semelhante pode ser feito para a NUCI industrial da CNI:

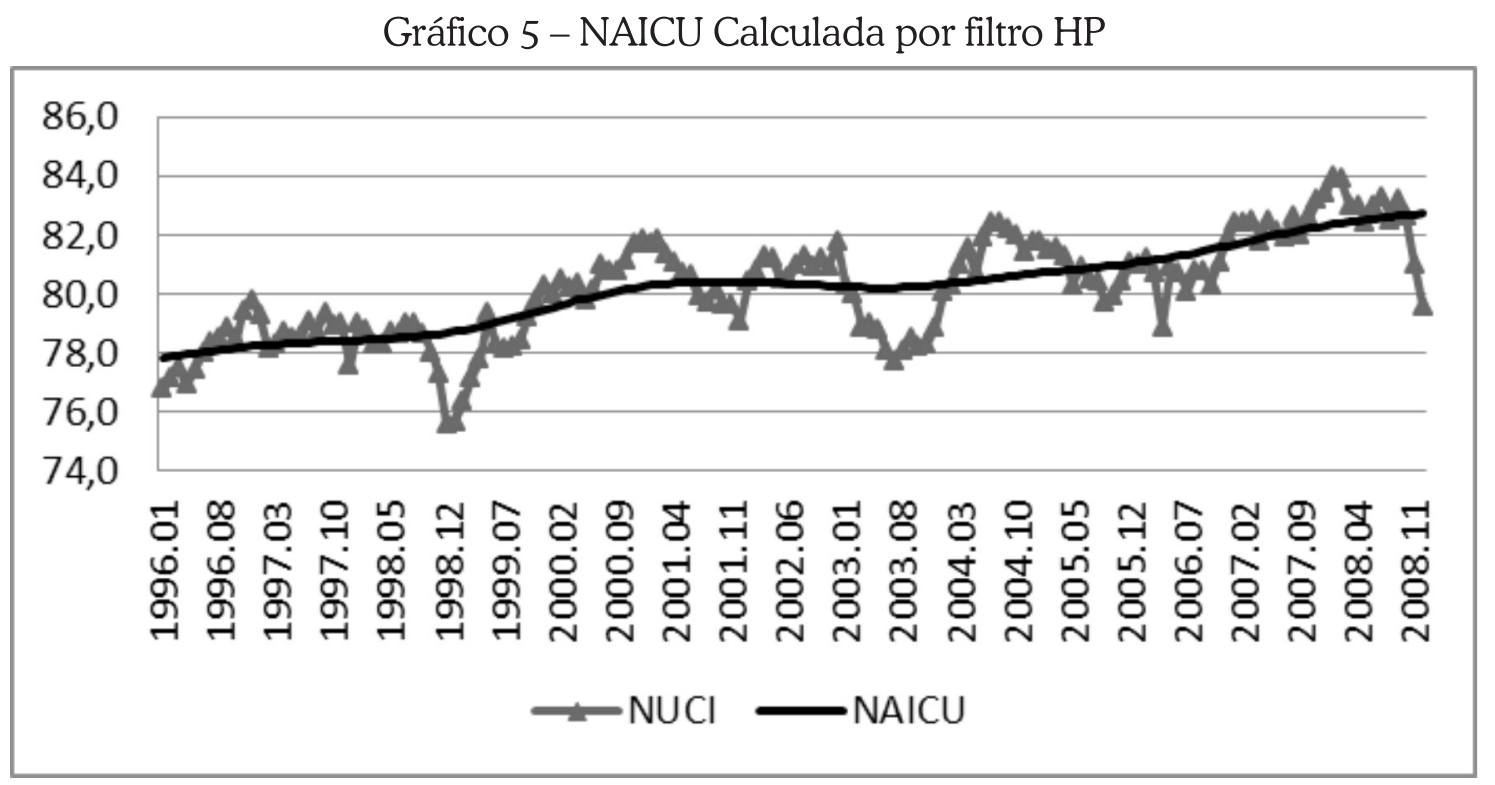

Fonte: Elaboração própria a partir de dados do CNI. 
A NAICU será uma espécie de média móvel da taxa histórica do nível de utilização da capacidade instalada. Em períodos em que o NUCI aumenta, a NAICU aumenta e em períodos em que a taxa de desemprego é mais baixa, a NAICU diminui. A NAICU, que por definição é nível de utilização da capacidade que não acelera a inflação, nesse caso também será obtido sem nenhuma relação com inflação.

Os resultados de hiato do produto obtidos por esse método - que acrescenta mais elementos estatísticos no método econômico - são muito mais simétricos que o método "Silva Filho", porém não tão simétricos quanto o método puramente estatístico.

Gráfico 6 - Produto potencial calculado por Souza Jr (PTF, NAIRU e NAICU endógenas) Hiato do produto: SCN referência 1985 versus SCN referência 2000

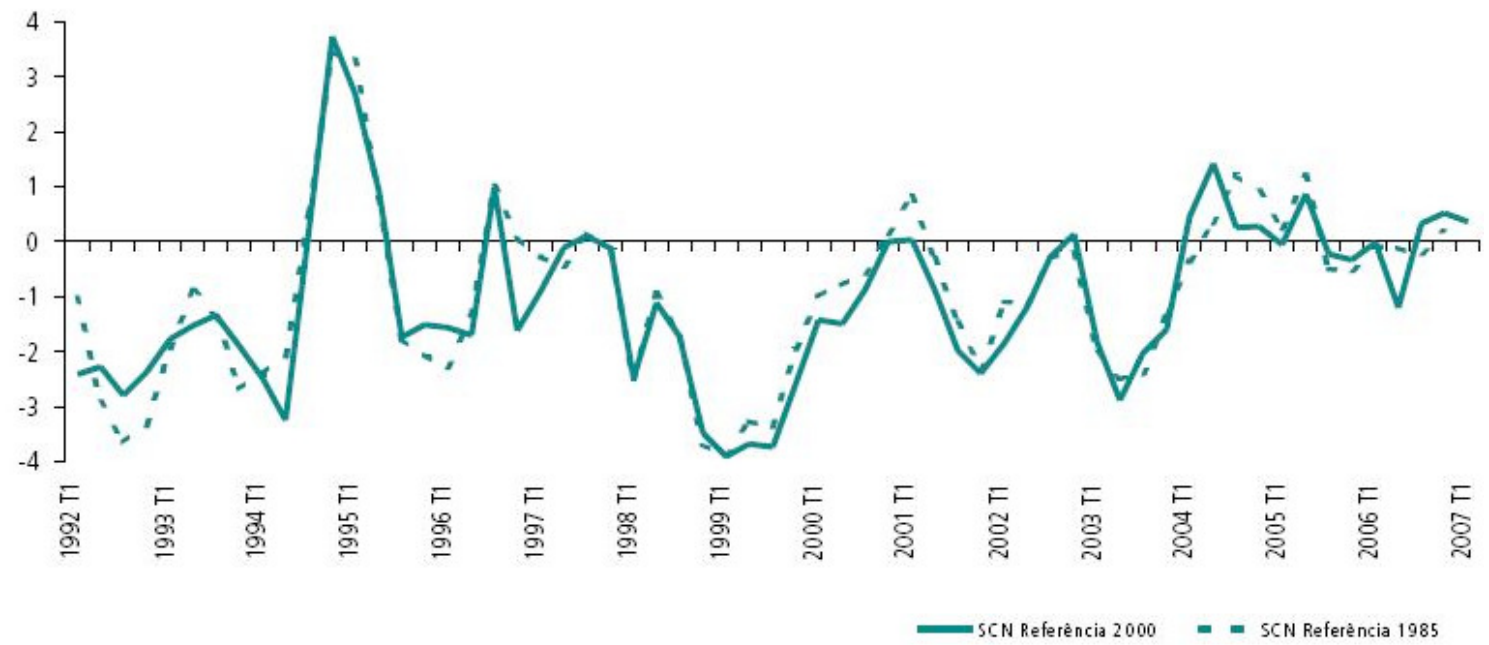

Fonte: Souza Junior (2006).

O PIB potencial nesse caso é mais dependente do andamento corrente do PIB efetivo (mais endógeno, portanto) que aquele calculado por Silva Filho (2001). Afinal, além de depender da PTF calculada como resíduo do PIB efetivo, depende também do andamento médio do nível da utilização da capacidade instalada e da taxa de desemprego observadas, que são fortemente influenciados pela demanda efetiva. O corolário da utilização desse método, ao contrário do que parece acreditar o autor ${ }^{29}$, é que se a economia mudar de patamar e passar a operar com taxas mais baixas de desemprego e/ou níveis mais altos de utilização de capacidade, o

29 Souza Junior (2007, p. 84) conclui que "[...] para que o PIB possa crescer, de forma sustentável, em torno de 4,5\% e 5\% nos próximos anos, será necessário estimular o aumento da produtividade e dos investimentos." Mas tal resultado não condiz com modelo proposto pois, se taxa de desemprego natural e NAICU são dados pela tendência de suas taxas efetivas, a utilização desses recursos em níveis mais elevados por si só já resultaria em um produto potencial maior. 
filtro HP irá computar essa média móvel dessas variáveis como NAIRU mais baixa e NAICU mais alta, e assim, o produto potencial aumenta pela via da demanda.

Resultados mais recentes que utilizam o método "Souza Junior", como o trabalho de Pastore e outros (2008), corroboram essa afirmação. Pastore et al. (2008) mostram que o PIB potencial brasileiro passou de uma média de $2,3 \%$ no período 2000-2004 para uma média de 3,6 no período 2005-2006 e 4,1 para 2007-2008, seguindo a tendência de crescimento do produto efetivo ${ }^{30}$.

\subsubsection{Implicações teóricas do uso de filtros estatísticos}

Vimos que o modelo do Novo Consenso em política econômica postula a existência de um produto potencial que evolui segundo variáveis mais estruturais de oferta, como a dotação dos fatores de produção, a eficiência de sua utilização e os níveis de utilização do trabalho e capital não aceleradores de inflação (NAIRU e NAICU). A demanda efetiva e o produto corrente não conseguem influenciar o produto potencial por este modelo.

A aplicação de filtros estatísticos em séries que compõem o produto potencial pela Função de produção, presente nos trabalhos de Souza Junior (2005, 2006, 2007), geram por um lado hiatos mais simétricos, mas abandonam a teoria do produto potencial exógeno uma vez que o produto potencial depende do andamento das séries correntes (taxa de desemprego, NUCI e produto efetivo), que são altamente influenciadas pela demanda agregada. Isso gera um conflito teórico com o modelo do Novo Consenso, uma vez que nesse modelo tanto o produto corrente como a demanda agregada não tem nenhum efeito sobre o produto potencial de longo prazo ${ }^{31}$.

30 Areosa (2004) propõe um método de estimação ainda mais endógeno que o de Souza Junior. Para obter o produto potencial, basta aplicar um filtro HP multivariado que extrai a tendência das séries de produto, emprego e utilização de capacidade efetiva ponderados pelo parâmetro de contribuição do capital e do trabalho ao produto. O resultado final é a estimação das séries de produto potencial, NAIRE (nível de emprego que não acelera a inflação) e NAICU, que são tendências que se movem de maneira parecida com as séries efetivas. Esse produto potencial gerado é ainda mais endógeno que aquele estimado por Souza Junior, pois não leva em conta os estoques de fatores, mas apenas uma média móvel calculada pela ponderação de três séries efetivas.

31 O caso brasileiro analisado acima apenas repete os problemas com esses métodos de estimação em outros países do mundo (Ver Palumbo (2008) para uma resenha). 
Quadro 1 - Comparativo dos trabalhos empíricos que estimam o Produto Potencial do Brasil

\begin{tabular}{|c|c|c|c|c|c|}
\hline & Silva Filho & Barroso & Souza Jr & Aerosa & Lima e Brito \\
\hline Método & $\begin{array}{l}\text { Função de } \\
\text { Produção - } \\
\text { exógeno }\end{array}$ & $\begin{array}{l}\text { Função de } \\
\text { Produção - } \\
\text { exógeno }\end{array}$ & $\begin{array}{l}\text { Função de } \\
\text { produção } \\
\text { com filtro }\end{array}$ & $\begin{array}{l}\text { Função de } \\
\text { produção } \\
\text { com filtro }\end{array}$ & $\begin{array}{l}\text { Filtro multiva- } \\
\text { riado }\end{array}$ \\
\hline $\begin{array}{l}\text { Estoques } \\
\text { dos fatores }\end{array}$ & Calculados & Calculados & Calculados & - & - \\
\hline Alfa & $\begin{array}{l}\text { Contas } \\
\text { nacionais - } \\
\text { hipótese de } \\
\text { equilíbrio } \\
\text { com maximi- } \\
\text { zação }\end{array}$ & $\begin{array}{l}\text { Contas } \\
\text { nacionais - } \\
\text { hipótese de } \\
\text { equilíbrio } \\
\text { com maximi- } \\
\text { zação }\end{array}$ & $\begin{array}{l}\text { Contas } \\
\text { nacionais - } \\
\text { hipótese de } \\
\text { equilíbrio com } \\
\text { maximização }\end{array}$ & & - \\
\hline PTF & $\begin{array}{l}\text { Resíduo do } \\
\text { produto - } \\
\text { endógena }\end{array}$ & $\begin{array}{l}\text { Resíduo do } \\
\text { produto - } \\
\text { endógena }\end{array}$ & $\begin{array}{l}\text { Resíduo do } \\
\text { produto - } \\
\text { endógena }\end{array}$ & - & - \\
\hline $\begin{array}{l}\text { NAIRU e } \\
\text { NAICU }\end{array}$ & Valor fixo & Valor fixo & $\begin{array}{l}\text { Filtro HP das } \\
\text { séries de taxa } \\
\text { de desempre- } \\
\text { go e utilização } \\
\text { da capaci- } \\
\text { dade }\end{array}$ & $\begin{array}{l}\text { Filtro HP } \\
\text { das séries de } \\
\text { utilização da } \\
\text { capacidade e } \\
\text { emprego }\end{array}$ & - \\
\hline $\begin{array}{l}\text { Outras } \\
\text { variáveis }\end{array}$ & - & - & - & $\begin{array}{l}\text { Produto } \\
\text { efetivo }\end{array}$ & $\begin{array}{l}\text { Taxa de infla- } \\
\text { ção }\end{array}$ \\
\hline $\begin{array}{l}\text { Endoge- } \\
\text { neidade }\end{array}$ & $\begin{array}{l}\text { Método mais } \\
\text { exógeno, } \\
\text { apenas a PTF } \\
\text { é endógena }\end{array}$ & $\begin{array}{l}\text { Método mais } \\
\text { exógeno, } \\
\text { apenas a PTF } \\
\text { é endógena }\end{array}$ & $\begin{array}{l}\text { Método mais } \\
\text { endógeno; } \\
\text { PTF, NAIRU e } \\
\text { NAICU calcu- } \\
\text { ladas a partir } \\
\text { de séries } \\
\text { efetivas }\end{array}$ & $\begin{array}{l}\text { Método } \\
\text { ainda mais } \\
\text { endógeno, } \\
\text { pois é apenas } \\
\text { filtro multi- } \\
\text { variado das } \\
\text { séries de pro- } \\
\text { duto efetivo, } \\
\text { emprego e } \\
\text { utilização da } \\
\text { capacidade } \\
\text { ponderados } \\
\text { por alfa }\end{array}$ & $\begin{array}{l}\text { Também endó- } \\
\text { geno. NAILO é } \\
\text { calculada pela } \\
\text { aplicação de } \\
\text { filtro multiva- } \\
\text { riado na série } \\
\text { de produto } \\
\text { efetivo levan- } \\
\text { do em conta } \\
\text { variação de } \\
\text { inflação }\end{array}$ \\
\hline $\begin{array}{l}\text { Resultados } \\
\text { empíricos }\end{array}$ & $\begin{array}{l}\text { Hiatos assi- } \\
\text { métricos e na } \\
\text { maior parte } \\
\text { da amostra, } \\
\text { negativos }\end{array}$ & $\begin{array}{l}\text { Hiatos } \\
\text { assimétricos } \\
\text { e em toda } \\
\text { amostra, } \\
\text { negativos }\end{array}$ & $\begin{array}{l}\text { Hiatos um } \\
\text { pouco mais } \\
\text { simétricos, } \\
\text { com maior } \\
\text { incidência de } \\
\text { casos positivos }\end{array}$ & $\begin{array}{l}\text { Hiatos simé- } \\
\text { tricos }\end{array}$ & $\begin{array}{l}\text { Hiatos simé- } \\
\text { tricos, grande } \\
\text { variabilidade } \\
\text { no começo da } \\
\text { amostra (antes } \\
\text { do plano Real) }\end{array}$ \\
\hline
\end{tabular}

Fonte: Elaboração própria. 


\section{Considerações Finais}

Vimos que o modelo novo-keynesiano e sua versão recente do Novo Consenso em política econômica - que embasa teoricamente a atuação de Bancos Centrais de diversos países, inclusive o Banco Central do Brasil - postula a existência de um produto potencial que evolui segundo variáveis mais estruturais de oferta, como a dotação dos fatores de produção, a eficiência de sua utilização e os níveis de utilização do trabalho e capital não aceleradores de inflação (NAIRU e NAICU). A demanda efetiva e o produto corrente não conseguem influenciar o produto potencial por este modelo.

Os modelos de produto potencial estimados para o Brasil também demonstram dificuldades empíricas e teóricas. Afinal, o modelo de produto potencial mais exógeno $\mathrm{o}^{32}$ e calculado segundo os fatores de oferta, estimado por Silva Filho, quando calculado gera resultados de hiatos negativos e persistentes para quase toda a amostra, o que deveria estar combinado com uma grande desaceleração da inflação, fato que não ocorreu no período em análise. Por outro lado, o método de Souza Junior $(2005,2006,2007)$, que gera hiatos mais simétricos, acabam tendo que recorrer à utilização de filtros estatísticos para a estimação da NAIRU e NAICU, e assim fazendo com que o produto potencial dependa do andamento do produto corrente (uma vez que este afeta, além da PTF calculada como resíduo, a taxa de desemprego efetiva e o grau de utilização da capacidade efetivo). Isso gera um conflito teórico com o modelo do Novo Consenso, uma vez que nesse modelo tanto o produto corrente como a demanda agregada não tem efeito no produto potencial de longo prazo.

Temos, portanto, duas opções não satisfatórias. Por um lado, ao estimar o produto potencial pelo método mais exógeno e seguir a base teórica, ocorrem problemas com as evidências empíricas, uma vez que os hiatos gerados são assimétricos e incompatíveis com a inflação brasileira, pois deveria ocorrer uma grande desaceleração da inflação no período recente. Por outro lado, a tentativa de remediar e tornar os hiatos mais simétricos requer a utilização de filtros estatísticos, que no fim das contas são médias móveis mais sofisticadas das séries correntes, e, portanto, o produto potencial passa a conter elementos endógenos, e, portanto, contrário a teoria que o sustenta.

Deve-se notar que o caso brasileiro analisado acima apenas repete os problemas com esses métodos de estimação em outros países do mundo (PALUMBO, 2008) para uma resenha. Porém, já que a prática muitas vezes impõe a necessidade de calcular o produto potencial de maneira endógena para se adequar às evidências empíricas, e que este método acaba sendo aceito sem muita contestação

32 É mais exógeno que os outros, porém não totalmente exógeno uma vez que a própria PTF, da maneira como é calculada, é correlacionada com o produto efetivo. 
nos estudos pragmáticos para propósito de orientação da condução de políticas econômicas, convém ressaltar que este método é compatível com a teoria do crescimento liderado pela demanda.

Assim, o que poderia parecer uma solução insatisfatória para a teoria do produto potencial exógeno, é perfeitamente compatível com teorias que admitem a importância do papel da demanda efetiva na determinação da capacidade de produção de longo prazo. Dessa maneira, uma outra alternativa de estimação do produto potencial para o Brasil que pode ser investigada pode partir da ideia de que o crescimento do estoque de capital no longo prazo é liderado pela demanda efetiva, em uma perspectiva da Economia Política Clássica (abandonando o efeito substituição e a tendência ao pleno emprego dos fatores), levando em conta, assim, tanto a perspectiva crítica de que o produto potencial depende apenas do estoque de capital (e não da força de trabalho) quanto os efeitos do investimento induzido, e seu efeito sobre o crescimento do estoque de capital e, consequentemente, da capacidade produtiva. Avaliar os limites do crescimento da capacidade produtiva liderado pela demanda efetiva dentro desse contexto teórico nos parece bastante instigante, mas esse é um tema que deve ser deixado para outro trabalho.

\section{Referências}

ARAÚJO, C.; AREOSA, M.; GUILLÉN, O. Estimating potential output and the output gap for Brazil. In: ENCONTRO NACIONAL DE ECONOMIA, 32, João Pessoa, 2004. Anais... João Pessoa: ANPEC, 2004.

ARAÚJO, C. H. V.; GUILLÉN, O. T. C. Previsão de inflação com incerteza do hiato do Produto no Brasil. In: ENCONTRO NACIONAL DE ECONOMIA, 36, Salvador, 2008. Anais... Salvador: ANPEC, 2008.

AREOSA, M. B. M. Combining Hodrick-Prescott filtering with a production function approach to estimate output gap. Rio de Janeiro: BACEN, 2004. (Technical Note).

BANCO CENTRAL DO BRASIL.Metodologias para estimação do produto potencial. Relatório de Inflação, Brasília, v. 1, n. 3, p. 75-78, set. 1999.

Cálculo do produto potencial pelo método da função de produção: resultados para

o Brasil. Relatório de Inflação, Brasília, v. 2, n. 4, dez. 2000.

. Metodologias para estimação do produto potencial. Relatório de Inflação, Brasília, v. 5, n. 4, p. 117-120, dez. 2003.

. PIB potencial e hiato do produto: atualização e novas estimações. Relatório de Inflação, Brasília, v. 6, n. 3, p. 112-114, set. 2004.

. Hiato do produto: atualização e novas estimações. Relatório de Inflação, Brasília, v. 7, n. 3, p. 106-107, set. 2005.

. Estimação do hiato do produto: modelo de componentes não observados. Relatório

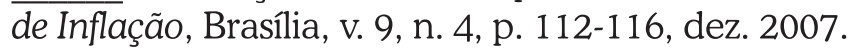


BARBOSA-FILHO, N. H. Estimating potential output: a survey of the of the alternative methods and their applications to Brazil. Rio de Janeiro: IE-UFRJ, 2004. (Textos para Discussão)

. Estimando e revisando o produto potencial do Brasil: uma análise do filtro HodrickPrescott com função de produção. In: GENTIL, D.; MESSENBERG, R. (Org.) Crescimento econômico: produto potencial e investimento. Rio de Janeiro: IPEA. 2009.

BARROSO, R. Produto potencial: conceitos, novas estimativas e considerações sobre sua aplicabilidade. Revista EconomiA, Brasília, v. 8, n. 3, p. 437-462, set./dez. 2007.

BASTOS, C. Inflação e estabilização. In: FIORI, J.; MEDEIROS, C. (Ed.). Polarização mundial e crescimento. São Paulo: Vozes, 2001.

BEVILAQUA, A.; MESQUITA, M.; MINELLA, A. Brazil: taming inflation expectations. Working Paper Series, Brasília, n. 129, p. 1-39, jan. 2007.

BILLMEIER, A. Ghostbusting: which output gap measure really matters? IMF Working Papers, Washington, n. 146, 2004.

BLINDER, A. Is there a core of practical macroeconomics that we should all believe? American Economic Review, Nashville, v. 87, n. 2, p. 240-43, May 1997.

BOGDANSKY, J.; TOMBINI, A.; WERLANG, S. Implementing inflation targeting in Brazil. Working Paper Series, Brasília, n. 77, p. 1-38, jul. 2000.

BRAGA, J. M. Raiz unitária, inércia e histerese: o debate sobre as mudanças da NAIRU na economia americana nos anos 1990. 2006. Tese (Doutorado em Economia) - Instituto de Economia, Universidade Federal do Rio de Janeiro, Rio de Janeiro, 2006.

CESARATTO, S.; SERRANO, F. As leis de rendimento nas teorias neoclássicas do crescimento: uma crítica sraffiana. Ensaios FEE, Porto Alegre, v. 23, n. 2, 2002.

CARLIN, W.; SOSKICE, D. Teaching intermediate macroeconomics using the 3-equation model. In: FONTANA, G.;SETTERFIELD, M. Macroeconomic theory and macroeconomic pedagogy. Basingstoke: Palgrave MacMillan, 2010.

LIBÂNIO, G. Aggregate demand and the endogeneity of the natural rate of growth: evidence from Latin American economies. In: ENCONTRO NACIONAL DE ECONOMIA, POLÍTICA, 13., João Pessoa, 2008. Anais... João Pessoa: SEP, 2008.

LIMA, E. C. R. Inflação, nível de atividade e o produto potencial no Brasil. Boletim de Conjuntura, Rio de Janeiro, v. 53, 2001.

LIMA, E.; BRITO, L. Inflação e nível de atividade no Brasil: estimativas via curva de Phillips. In: ENCONTRO NACIONAL DE ECONOMIA, 36., Rio de Janeiro. Seminário de Pesquisa. Rio de Janeiro: IE/UFRJ, 2008.

LUCAS, G. O debate sobre o produto potencial no Brasil. 2008. Trabalho de Conclusão de Curso (Graduação em Economia) - Instituto de Economia, Universidade Federal do Rio de Janeiro, Rio de Janeiro, 2008.

MANKIW, N. Macroeconomics. 7. ed. New York: Worth Publishers, 2010.

MOREIRA, T.; SOUZA, G.; ALMEIDA, C. The fiscal theory of the price level and the interaction of monetary and fical policies: the Brazilian case. Brazilian Review of Econometrics, Rio de Janeiro, v. 27, n. 1, p.85-106, 2007.

OKUN, A. M. Potential GNP: its measurement and significance. Cowles Foundation Paper, New Haven, n. 190, 1962. 
PALUMBO, A. I metodi di stima del PIL potenziale tra fondamenti di teoria economica e contenuto empírico. Working paper, Roma, n. 92, Oct. 2008.

PASTORE, A.; PINNOTTI, M.; ALMEIDA, L. Crescimento, contas correntes e política fiscal. In: VELLOSO, J. P. R. O Brasil e a economia criativa: um novo mundo nos trópicos. Rio de Janeiro: José Olympio, 2008. (Estudos e pesquisas, n. 215)

PORTUGAL, P. Estimação dos parâmetros das curvas IS e de Phillips da economia brasileira: 1994/2001. 2005. Dissertação (Mestrado em Economia) - Escola de Pós-Graduação em Economia, Fundação Getúlio Vargas, Rio de Janeiro, 2005.

ROMER, D. Keynesian and macroeconomics without the LM curve. The Journal of Economic Perspectives, Nashville, v. 14, n. 2, p.149-169, June/Sept. 2000.

SERRANO, F. Equilíbrio neoclássico de mercado de fatores: um ponto de vista sraffiano Ensaios FEE, Porto Alegre, v. 22, n. 1, 2001.

SERRANO, F. Histéresis, dinámica inflacionaria y el supermultiplicador sraffiano. Buenos Aires: Edicionones Cooperativas, 2007. (Seminários Sraffianos, n. 2).

SERRANO, F.; BRAGA, J. Some evidence on how inflation targeting really works in Brazil. In: SEMINÁRIO INTERNACIONAL DO CCJE-UFRJ, Rio de Janeiro, dez. 2008. Apresentação.

SILVA FILHO, T. N. T. Estimando o produto potencial brasileiro: uma abordagem da função de produção. Brasília: BACEN, 2001. (Texto para Discussão, 17).

SOUZA JUNIOR, J. R. C. Produto potencial: conceitos, métodos de estimação e aplicação à economia brasileira. Rio de Janeiro: IPEA, 2005. (Texto para Discussão, n. 1130).

. Cenários para o crescimento do produto potencial de 2007 a 2010. Boletim de Conjuntura, Rio de Janeiro, n. 75, 2006.

. Estimativa do produto potencial para a economia brasileira: atualização utilizando o sistema de contas nacionais referência 2000. Boletim de Conjuntura, Rio de Janeiro, n. 77, 2007.

SOUZA JUNIOR, J. R. C.; JAYME JUNIOR, F. G. Constrangimentos ao crescimento no Brasil: um modelo de hiatos (1970-2000). Revista de Economia Contemporânea, Rio de Janeiro, v. 8, n. 1, p. 33-65, jan./jun. 2004.

TAYLOR, J. B. A core of practical macroeconomics. American Economic Review, Nashville, v. 87, n.2, p. 233-235, May 1997.

Teaching modern macroeconomics at the principles level. American Economic Review, Nashville, v. 90, n.2, p. 90-94, May 2000.

Recebido em: 03/02/2010.

Aceito em: 20/09/2011. 